\title{
Da Vida e suas Explicações - Irreversibilidade e Reducionismo
}

\author{
A. M. AMORIM D A COSTA*
}

"O universo da energia tende para um equilíbrio no qual a vida não pode existir"

(C.Sherrington)

\section{INTRODUÇÃO}

Por referência aos cem anos decorridos sobre a Lição de F. R. Japp na abertura do LXVII Encontro da Associação Britânica para o Avanço da Ciência, na cidade de Bristol (Inglaterra), em 1898, subordinada ao título "Stereochemistry and Vitalism", publicámos nas páginas deste Boletim da Sociedade Portuguesa de Química algumas considerações sobre a vida e suas explicações [1]. Na generalidade com que abordámos o tema, a parte de leão das considerações tecidas coube às posições do Vitalismo, levando em conta o teor da Lição de Japp que as suscitou. A questão do reducionismo pouco mais foi que aflorada com a afirmação quase gratuita de que "a vida não desafia as leis fundamentais da física, o que não quer dizer que as leis da física a expliquem facilmente" [2].

Por isso resolvemos retomar o assunto, dando agora maior relevo às posições reducionistas.

\section{O MECANISMO DA EVOLUÇÃO MOLECULAR}

Todo o Universo é feito de átomos e moléculas em constante movimento. Consequentemente, o movimento é característica intrínseca de todos os corpos, os vivos e os nãovivos. Só em sentido estritamente científico que nāo em sentido vulgar do termo, por referência ao estado de inércia, a matéria inanimada pode ser referida como a matéria "inerte". Longe vai o tempo em que era possível caracterizar o ser vivo debitando a secular afirmação de Aristóteles "vita est in motu", a "vida está no movimento": como longe vai o tempo em que a vida era pensada e referenciada em termos do movimento regular de todo um conjunto de líquidos na complexa rede de canais do tecido orgânico, fosse ele vegetal ou animal, como o fez toda uma geração de químicos formados na escola de Boerhaave (1668-1738) para quem "assim que o movimento dos líquidos (que circulam no organismo dos seres vivos) se torna irregular, ou cessa em qualquer parte que seja, ele está doente, e assim que esse movimento para em todo o corpo, ele morre" [3].

Os átomos e moléculas componentes da matéria viva são os mesmos que compõem a matéria nãoviva e o movimento incessante que os informa rege-se, num caso e noutro, pelas mesmas leis da física. Nos seres vivos, como em qualquer ser inanimado, não há nem aniquilação, nem criação de massa ou de energia. Em ambos se cumprem de igual modo os princípios de conservação de uma e outra, nas diferentes trocas que os envolvem. E porque vivem e agem num ambiente que está longe de se encontrar num estado de perfeito equilíbrio físico e químico, a existência dos seres vivos não contraria o Segundo Princípio da Termodinâmica que restringe a direcção das transformaçōes da energia [4].

Todavia, pese embora o avanço da ciência, e em particular o desenvolvimento da bioquímica molecular nos permitir, hoje, descrever em termos moleculares bastante precisos muitos dos processos fundamentais da vida, as leis da física que conhecemos não nos permitem ainda descrever satisfatoriamente muitas das características essenciais do comportamento da matéria viva. Quer dizer, a explicação da vida pelas leis da física que hoje conhecemos está longe de ser um dado adquirido.

De facto, são muitas as questões relacionadas com o comportamento dos seres vivos para as quais não temos ainda uma explicação cabal em termos das leis físicas conhecidas. Acreditamos que o número dessas questões irá diminuindo drasticamente com o progresso da ciência, mas não podemos garantir, em termos de certeza, que ele se venha a tornar nulo, posto que nem sequer podemos garantir que ele possa, de facto, ser nulo.

Que os elementos naturais componentes da matéria viva e da matéria não-viva, tomados na sua individualidade, obedecem às mesmas leis da física, não sofre, hoje, qualquer contestação. Mas, é também incontestável que o comportamento colectivo do ser vivo poderá não ser compreensível em termos das partes que o constituem. Se não está em causa que num caso e noutro os constituintes básicos são exactamente o mesmo tipo de átomos, sujeitos às mesmas leis da física [5], não é fácil explicar como pode um único conjunto de leis induzir comportamentos tão diferentes do vivo para o não vivo, e vice-versa. No processo de replicação que caracteriza especificamente o ser vivo, a matéria evolui para estados progressivamente mais ordenados, em auto-organização espontânea; no ser não-vivo, ressalvada uma mão cheia de conhecidas excepções, toda a evolução natural dáse no sentido de estados cada vez mais desordenados.

Quer dizer, para explicarem a vida as leis da física terão de ser capazes de poder explicar a auto-organização espontânea. A estrutura auto-organizada em que se consubstancia o ser vivo não é a mera soma das suas partículas, como uma melodia não é a simples soma dos sons que a compõem.

Schrödinger disse-o com toda a clareza, já lá vão umas décadas de anos: a ordem que se nos depara no desenrolar da vida dimana de uma fonte muito diversa daquela que se nos depara no desenrolar do evoluir natural da matéria inanimada. "O organismo vivo alimenta-se de entropia negativa"[6].

Na sua evolução natural, qualquer organismo vivo produz entropia positiva, aproximando-se, dia a dia, como o universo em geral, dum estado perigoso de entropia máxima que significa morte; todavia, graças ao metabolismo que o mantém vivo, contraria, também dia a dia, o evoluir natural, extraindo continuamente do seu ambiente entropia negativa. 
Esta é a sua "maravilhosa faculdade" que adia, no dia a dia, a sua queda no equilíbrio termodinâmico em que se aniquila o que faz dele um servivo. Enquanto a entropia negativa que extrai do meio ambiente equilibrar a entropia positiva que se liberta no seu evoluir natural, mantém-se num nível de entropia estacionário e relativamente baixo.

Porque a "entropia negativa", expressão considerada grosseira por muitos cientistas, pode ser tomada em si mesma como uma medida de ordem, podemos dizer que no processo metabólico que o anima, o ser vivo absorve continuamente ordem do meio ambiente que o rodeia. De facto, na sua generalidade, os compostos orgânicos mais ou menos complexos que "alimentam" o processo metabólico são compostos nos quais a matéria atinge um elevado grau de ordem ou regularidade. Uma vez utilizados, voltam a um estado muito mais simples, por degradação, no todo ou em grande parte, da ordem que possuíam.

É a “ordem a partir da ordem" em contraposição à "ordem a partir da desordem" também dita "ordem por flutuação".

E de imediato se nos depara a possibilidade de dois "mecanismos" diferentes através dos quais se podem produzir os fenómenos ordenados: o "mecanismo estatístico ou da probabilidade" que dá origem à "ordem a partir da desordem", e um outro que conduz à "ordem a partir da ordem". O primeiro comporta facilmente os fenómenos naturais e o seu carácter irreversível; o segundo, o "fluxo de organização" que atravessa o evoluir dos seres vivos. Mas impõe-se perguntar: será que dois mecanismos totalmente diferentes se podem explicar pelo mesmo tipo de leis físicas?

\section{1 - A ordem a partir da desordem}

"O movimento browniano de uma pequena partícula suspensa num liquido revela-se completamente irregular. Mas, se houver muitas partículas semelhantes, vão dar origem, devido ao seu movimento irregular, ao fenómeno regular da difusão". Deparamos aqui com "uma irregularidade completa que coopera apenas na produção de uma regularidade de grau médio"[7]. O mesmo se verifica em muitas outras situações, a nível macroscópico, decorrentes de um "comportamento irregular" de partículas a nível microscópico, conhecido, por isso mesmo, por caos molecular.

A Física newtoniana e a Mecânica quântica, no seu conteúdo determinista, sempre sentiram um certo mal-estar quando confrontadas com este tipo de ordem, a "ordem por flutuação", não obstante a aplicação que as leis de uma e outra fazem da lei dos grandes números. A ideia de um universo estático com todas as transformações naturais, por mais complexas que sejam a ser descritas em termos de trajectórias deterministas ou por "pacotes" de onda, cujo movimento é, num caso e noutro, inteiramente reversível, em que o presente determina, de uma maneira simétrica, tanto o futuro como o passado, decorre duma lei dinâmica reversível. Ora, a "ordem por flutuação" implica trajectórias dinâmicas em que não é possível evitar, em muitos casos, a irreversibilidade do crescimento entrópico[8].

A lei geral das trajectórias deterministas da Física Clássica ou da Mecânica Quântica que determina a passagem dum sistema entre dois estados instantâneos sucessivos, quaisquer que sejam, permite à trajectória definida desdobrar-se de estado em estado, tanto para o passado como para o futuro. O futuro e o passado desempenham nela o mesmo papel. A definição de um estado instantâneo em termos das posições das partículas do sistema contém de igual modo o passado e o futuro em que cada estado pode ser tratado como um estado inicial ou um estado resultante de uma longa evolução.

A situação é diferente no caso das trajectórias dinâmicas que descrevem processos em que a irreversibilidade do crescimento entrópico tenha lugar, qual é o caso dos processos em que ocorrem a ordem por flutuação, processos que trabalham a matéria, reacções químicas, condução, decomposiçōes radioactivas, etc. Aqui, próximo do estado de equilíbrio para que tendem, nada há a observar ao carácter universal das leis físicas que se the aplicam; porém, para além do limiar de estabilidade, isto é, longe do estado de equilíbrio. a universalidade dessas mesmas leis dá lugar, muitas vezes, à ocorrência de comportamentos qualitativamente diversos que dependem não só de transformações dissipativas possíveis, como também do próprio passado do sistema. Nelas, o determinismo dinâmico dá lugar a uma dialéctica complexa entre acaso e necessidade. onde as leis médias deterministas se revelam inteiramente satisfatórias nas regiões entre bifurcações do sistema, mas nem sempre são suficientes para explicarem cabalmente as ocorrências nas regiões de instabilidade cuja actividade produz novidade e onde a evolução do sistema "é inovação, criação e destruição, nascimento e morte", para usar as próprias palavras do autor que mais se tem devotado ao estudo aturado deste tipo de situações, Ilya Prigogine[9]. Esta é uma evolução irreversível que não é possível descrever em termos das leis reversíveis da dinâmica.

O devir irreversível é específico do chamado "mundo dos processos complexos" a que são intrínsecas flutuações comportamentais dos elementos componentes, em contraposição com o devir reversível do mundo das trajectórias da dinâmica determinista. Será que em ambas as situações as mesmas leis gerais da física serão aplicáveis em toda a sua extensão e do mesmo modo? Ou será que atingido um certo estágio elas "deixam" de se aplicar, por se revelarem incompletas e/ou inadequadas para a situação, ou mesmo por se revelarem inverazes?

Só um conhecimento mais profundo das condições de estabilidade das estruturas engendradas pelos processos irreversíveis, em certas circunstâncias, poderá permitir esboçar 
uma resposta à questão que assim se põe. Por ele passa, também, a possível redução dos processos auto-organizadores às leis da física.

Para ultrapassar o conceito de trajectória determinista, a física recorreu a uma descrição estatística, quer na Mecânica Clássica, quer na Mecânica Quântica, com particular realce para a introdução do conceito "operadores" que agem sobre funções e, com eles, as relações de incerteza e de complementaridade.

Se há operadores que comutam. há-os também que não comutam. Relativamente a grandezas correspondentes a estes últimos, só são possíveis informações estatísticas. A função de onda sobre que "operam" não é uma quantidade física observável em si, mas contém a evolução das diferentes probabilidades dos valores que podem tomar as grandezas observáveis. É a sua evolução que determina toda a mudança observável do sistema no decurso do tempo. Em estados estacionários a evolução do sistema é estritamente reversível; na mudança de um estado estacionário para outro, o sistema pode sofrer uma transformação irreversível.

Porque o mundo dinâmico, a nível microscópico, não é um mundo isolado, a reversibilidade e a irreversibilidade coexistem na sua evolução. A "desordem" a nível microscópico articula-se com a ordem a nível macroscópico. A nível microscópico, a ideia de uma determinação infinitamente precisa das condições iniciais necessárias à definição de trajectórias reversíveis não é apenas uma idealização; é uma idealização inadequada. Não conhecemos uma trajectória, mas um conjunto de trajectórias no espaço de fase. E neste, toda a região guarda uma riqueza de possibilidades qualitativamente diferentes, com possibilidade de criar movimentos também qualitativamente diferentes. Dois pontos tão chegados quanto se queira no espaço de fase, correspondendo a dois sistemas tão semelhantes quanto se deseje, podem, a todo o momento, orientarse em direcções diferentes. A evolução dinâmica de cada ponto é, certa- mente, determinista; porém, a descrição da evolução de toda a porção de espaço de fase em questão, tão pequena quanto se queira, tem um carácter estatístico a que não pode fugir, pois que a operação de passagem do conjunto à trajectória individual não pode ser efectuada. A fraca estabilidade do sistema confere-lhe um caracter aleatório irredutivel que o torna não-integrável [10].

Em vez duma dinâmica de trajectória temos, assim, uma dinâmica de funções de distribuição e de operadores que agem sobre elas. Nela, a entropia macroscópica de um sistema está ligada a um "operador" microscópico e a função de onda que a descreve corresponde a uma superposição das funções de onda próprias da mesma observável, a nível microscópico. Na sua individualidade, estas traduzem um estado de desordem, mas o valor próprio da superposição, o valor médio da função de onda a que se reduz a superposição, traduz um estado de ordem. É a "ordem por flutuação", a "ordem a partir da desordem".

O recurso a este tipo de "mecanismo estatístico" para explicá-la permite-nos compreender as linhas gerais do desenrolar dos fenómenos naturais, incluindo a sua irreversibilidade, em termos das leis físicas conhecidas.

\section{2 - A ordem a partir da ordem}

A racionalização do mecanismo da ordem por flutuação no quadro das leis da física hoje conhecidas que acabámos de referir mostra-nos, como dissemos, que o mundo dinâmico a nível microscópico não é um mundo isolado; na sua evolução, a reversibilidade e a irreversibilidade coexistem. Enquanto num sistema isolado o estado de máxima entropia "atrai" todo e qualquer outro estado de entropia menor, o mesmo não acontece necessariamente num mundo que não é isolado. Só assim podemos observar, na natureza, situações de evolução de menor ordem para maior ordem, qual é o caso dos fenómenos de auto-organização espontânea do processo de replicação que caracteriza os seres vivos.

Este nutre-se de fluxos que afastam do equilíbrio os sistemas físico-químicos em que se verifica, com rupturas de simetria e evoluções no sentido duma complexidade e diversidade crescentes [11].

A sucessão de fenómenos que se desenrolam durante o ciclo vital de um organismo mostra admirável ordem e regularidade sem qualquer paralelo no domínio da matéria inerte. Nessa sucessão, o ser vivo apresenta "uma assombrosa faculdade de concentrar em si próprio uma "corrente de ordem", escapando ao caos atómico"[12]. No ser vivo, a evolução de um estado bem ordenado para um outro também bem ordenado e até com um grau de ordem superior, num processo de auto-organização, aparece como "natural": as forças por ela responsáveis são, à temperatura em que existem como seres vivos, suficientemente poderosas para evitar a tendência para a desordem por parte da mobilidade térmica molecular.

Daqui se infere que a estrutura da matéria viva, sob a aç̧ão das forças que a caracterizam como tal, se comporta de maneira que não pode ser reduzida às leis físicas conhecidas. Não porque haja qualquer "força nova" que dirija o comportamento de cada átomo no seio do organismo vivo, mas porque a sua edificação é diferente da actuação normal, no quadro das leis físicas conhecidas[13]. No mecanismo da ordem por flutuação, o curso dos fenómenos em que há desordem atómica e molecular é uma regularidade média em que é patente a ausência duma determinação individual; de modo bem diferente, na "ordem a partir da ordem" que caracteriza o curso regular dos fenómenos inerentes ao servivo - o específico processo de replicação - um grupo de átomos existindo apenas num modelo ou cópia produz fenómenos ordenados e ajustados de maneira admirável entre si e em relação ao ambiente que se não coadunam com o "mecanismo pro- 
babilístico". A sua explicação requer inevitavelmente leis bem mais subtis [14].

Por mais subtis que possam ser essas leis, não podemos dizer, até prova em contrário, que sejam leis estranhas à física. Só o conhecimento cada vez mais profundo e pormenorizado da evolução das diversas formas de vida poderá levar à sua desejável compreensão e formulação. Para ele concorre, possivelmente mais do que nenhum outro, o conhecimento cada vez mais completo e preciso, sobretudo nos seus aspectos químicos, da origem e evolução dos compostos orgânicos a partir dos quais o processo replicativo se desenvolve.

\section{3 - A EVOLUÇÃo QUÍMICA}

Como já o referimos, a origem da vida é ainda um mistério científico cujo enigma central é o problema do limiar. Sabemos que a vida se afirmou só quando certas moléculas orgânicas formadas a partir de outras muito mais simples atingiram um certo nível muito elevado de complexidade, que só então foram capazes de incorporar uma vastíssima quantidade de informação de forma estável que viabilizou o armazenamento da cópia para replicação e os meios necessários para a efectivar [15].

Mas, como foi transposto o limiar desse nível de complexidade por processos físicos e químicos comuns? Em particular, quais os acontecimentos químicos que ocorreram na Terra prebiótica (ou qualquer outro local do Universo de onde os primeiros seres vivos terrestres possam ter sido importados) que determinaram o aparecimento da primeira célula viva?

A resposta a estas e outras perguntas do género prende-se com a questão da própria evolução do Universo. Como, quando e em que condições teve o seu início? Como e em que condições se processa, na teia de todo um conjunto de equilíbrios e desequilíbrios cuja caracterização termodinâmica envolve a complexa evolução da ordem a partir da desordem, como da desordem a partir da ordem? Não iremos referir-nos aqui a essa evolução, nem às teorias que pretendem explicá-la, a partir de pressupostos básicos. Limitar-nosemos a uma breve referência aos problemas da evolução química relacionados com essas questões.

A resposta possível às mesmas, no quadro da ciência actual, tem por base experiências laboratoriais em que se simula o presumível ambiente da Terra prebiótica. Tais experiências jogam com um conjunto de dados provenientes dos conhecimentos actuais em domínios científicos diversos, nomeadamente, no domínio da astronomia, da geologia, da biologia, da química orgânica e da química das radiações, e são o fundamento da chamada teoria da evolução química da vida que tem vindo a ser desenvolvida a partir da década de 1920 , na sequência, em particular, dos escritos de Oparin e Haldane defendendo, o primeiro em 1924, e o segundo em 1929, que a vida na Terra terá aparecido a partir duma "sopa prebiótica" de compostos orgânicos, formada em certos locais do planeta, particularmente nos oceanos, lagos e charcos [16-17].

Muito genericamente, de acordo com tal teoria, o primeiro ser vivo ter-se-ia formado na sequência duma evolução da matéria inerte em que seria possível distinguir as seguintes etapas fundamentais [18]:

(i) - formação de compostos orgânicos simples e voláteis, nomeadamente o formaldeído e o cianeto de hidrogénio, a partir dos elementos componentes, sob a influência de energias variadas;

(ii) - formação dos primeiros monómeros bioquímicos (aminoácidos, bases heterocíclicas e açúcares) a partir da dissolução em água dos compostos orgânicos simples antes formados;

(iii) - formação de polímeros de interesse biológico (peptídeos e polinucleótidos) por condensação dos monómeros bioquímicos anteriores; (iv) - aparecimento duma fase orgânica separada da fase aquosa que permitiu a diferenciação dos polímeros formados;

(v) aumento da complexidade dos mesmos, permitindo o estabelecimento de processos auto-catalíticos e levando ao aparecimento de estrtuturas auto-organizadas que por sua vez, terão levado à formação de sistemas auto-reprodutores, num processo de replicação - os primeiros seres vivos.

A viabilidade das primeiras quatro destas cinco etapas é hoje suportada por numerosos trabalhos experimentais e teóricos, na sequência da célebre experiência de Miller-Urey. em 1953, crédito bastante para a verosimilhança da "sopa prebiótica" primitiva[19], já referida no nosso trabalho anterior[20].

$\mathrm{O}$ aparecimento das estruturas auto-organizadas com a formação de sistemas auto-reprodutores a que se reporta a última das etapas evolutivas mencionadas é, hoje, a grande questão em aberto e objecto de numerosos trabalhos, quer a nível experimental, quer a nível teórico. A nível experimental, são de realçar as experiências com moléculas sintéticas produzidas em laboratório capazes de produzirem cópias de si-mesmas[21]. A nível teórico, impõe-se uma referência específica à já mencionada teoria das estruturas dissipativas de I. Prigogine.

\section{1 - A síntese abiogénica nas condições terrestres primitivas}

As investigações realizadas posteriormente à experiência de MillerUrey têm mostrado que a síntese dos constituintes básicos do ser vivo ou a dos seus precursores, nas condições terrestres primitivas, é um fenómeno natural desde que um número de condições fisico-químicas seja satisfeito.

O estado actual da ciência aponta no sentido de que a química dos fenómenos ocorridos nas condições terrestres primitivas tenha sido de- 
terminada pela natureza da atmosfera de então; a atmosfera terá sido a verdadeira controladora dos processos químicos que ocorreram no seu seio e também dos processos químicos que ocorreram simultaneamente, nos oceanos e nas rochas [22].

A mesma ciência indica que essa atmosfera era predominantemente uma atmosfera formada por hidrogénio. Aquando da formação da Terra, a maioria do carbono, azoto e oxigénio que nela existiam encontrar-seiam na forma de metano e outros hidrocarbonetos de cadeia carbonada curta, amoníaco e água [23]. Os intensos campos gravitacionais e as baixas temperaturas que então dominavam o planeta favoreciam a retenção de moléculas leves, tal como se verifica acontecer em nossos dias, por exemplo , no sistema de Júpiter[24].

Sob a acção de radiações ionizantes, nomeadamente radiações ultravioleta, ter-se-ão formado diversos compostos biologicamente importantes, v. g., aminoácidos, açúcares, purinas, etc. utilizados como primeiros "blocos" na construção da primeira célula viva. De início, os cromossomas que se terão formado terão operado num meio anaeróbico, o que significa que a divisão celular terá ocorrido durante um período temporário de anaerobiose[25]. Durante este período, que do ponto de vista da evolução química compreende cerca de um bilião de anos após o aparecimento da primeira célula viva, o carbono inicialmente existente na atmosfera na forma de metano e outros hidrocarbonetos, como dissemos, terá passado a existir predominantemente na forma de dióxido de carbono. Do ponto de vista químico, passouse, paulatinamente, duma atmosfera terrestre redutora para uma atmosfera terrestre oxidante, com uma camada de ozono, nas camadas superiores, protegendo o planeta das intensas radiações ultravioleta da luz solar. A radiólise ultravioleta do vapor de água existente na atmosfera e o progressivo desenvolvimento do processo de fotossíntese das plantas explicam tal transformação[26].

O mais provável é que a primitiva síntese abiogénica da primeira célula viva tenha ocorrido nos oceanos, onde primeiro se terá acumulado, por um processo natural de arrastamento e sedimentação, uma grande quantidade de compostos orgânicos e onde os primeiros amino-ácidos e açúcares facilmente poderiam absorver uma grande variedade de partículas inorgânicas existentes no depósito de lamas e argilas que lhes servia de fundo, simultaneamente matéria prima e catalítica do processo em curso. O seu desenvolvimento nas profundezas submarinas estava protegido da fotólise por radiação ultravioleta [27].

As suposições que acabámos de enunciar sobre a síntese e desenvolvimento abiogénicos da primeira célula viva têm vindo a ser testadas, cada vez com mais pormenor e eficácia, em laboratório.

Em trabalho publicado em 1828, Frederico Wöhler relatava a primeira síntese artificial de um composto orgânico, a ureia, que havia conseguido no seu laboratório, sem usar qualquer extracto animal|28].

A preparação artificial de compostos orgânicos a partir de material inorgânico sem intervenção de qualquer tipo duma possível "força vital" específica abriu perspectivas inteiramente novas à prática da química orgânica[29]. É, todavia, já na segunda metade do nosso século que se intensificam as sínteses abiogénicas, em laboratório, dos chamados biomonómeros (as unidades constituintes das proteínas, dos ácidos nucleicos e dos poli-sacarídeos), sob a aç̧ão de altas energias sobre misturas de metano - amoníaco - água.

As experiências efectuadas não só comprovam como explicam o possível mecanismo de ocorrência da síntese que poderá ter tido lugar na atmosfera terrestre prebiótica, de amino-ácidos[30], purinas e pirimidinas[31], açúcares[32], nucleótidos e nucleósidos, nomeadamente, ade- nosina, ribose e deoxiribose [33-34]. ácidos gordos[35-36], porfirinas[3738], proteínas [39-40] e ácidos nucleicos [41-42].

\section{2 - Evolução molecular e estruturas dissipativas}

Comprovada a possibilidade e compreendido o possível mecanismo da formação das bio-macromoléculas na atmosfera terrestre prebiótica, num processo de evolução química, fica por explicar a evolução do processo de auto-organização dessas mesmas macromoléculas para o complexo estado de ordem que caracteriza o ser vivo[43].

De acordo com a teoria "coarcevativa" de Oparin[44] e também de acordo com a teoria das "microsferas" (proteinodes), as "esférulas" formadas durante o arrefecimento de soluções aquosas saturadas de proteínas e outros compostos orgânicos afins, desenvolvida por Fox e colaboradores[45], a auto-organização verificada no evoluir dos seres vivos seria o resultado inevitável de forças de associação e organização inerentes ao processo químico da evolução dessas próprias moléculas. Que forças são essas? Qual a sua verdadeira natureza? Como comparam com os demais tipos de forças naturais?

A sua não caracterização satisfatória pelos autores que para elas apelam, deixa-nos naturalmente insatisfeitos e pouco significa do ponto de vista de explicação verdadeiramente científica.

Tentando uma explicação mais satisfatória, Ilya Prigogine desenvolveu a sua teoria das estruturas dissipativas a que fizemos já referência. Segundo esta teoria, a ordem complexa que caracteriza os sistemas biológicos teria a sua origem em processos físicos altamente desequilibrados do ponto de vista termodinâmico de cuja instabilidade resultaria uma organização espontânea em larga escala, sem necessidade de qualquer força vital específica.

A actividade química que cons- 
titui a actividade metabólica da célula viva é uma actividade altamente ordenada, tanto do ponto de vista da coordenação das diferentes velocidades das reacções, como do da sua localização na célula. A maioria das reacções em causa são reacções catalisadas, em que os catalisadores são, sobretudo, proteínas, em especial enzimas, em processos frequentemente auto-catalíticos, isto é, em que as moléculas reactivas activam elas próprias uma enzima estabilizando-a numa das suas múltiplas configurações possíveis, aquela a que seja mais acessível o local reactivo. Durante o processo reactivo, um produto da reacção pode "retroagir" sobre a velocidade da reacção que o fez aparecer.

Uma das propriedades notáveis dum sistema reactivo deste tipo, do ponto de vista da sua cinética química, é que as equações cinéticas que descrevem a sua evolução são equações diferenciais fortemente não-lineares.

Neste processo evolutivo não-linear a estabilidade não é um atributo de um estado como tal, envolvendo, sim, uma regressão de todas as flutuações possíveis. O sistema será instável se alguma das flutuações, em vez de regredir, se puder amplificar e invadir todo o sistema, fazendo-o evoluir para um novo regime de funcionamento qualitativamente diferente dos estados estacionários pelo mínimo de produção de entropia.

No domínio da termodinâmica linear, o fluxo entrópico é nulo quando o sistema atinge o equilíbrio e é uma função linear da força que o determina quando próximo do equilíbrio em que as forças por ele responsáveis são termodinamicamente muito fracas; não assim, no domínio da termodinâmica não-linear. Aqui, o modo como o fluxo entrópico depende da força que o determina é uma função bem mais complicada: na evolução global para o equilíbrio, mas ainda longe dele, os fluxos irreversíveis podem criar, de maneira previsível e reprodutível, a possibilidade de processos locais de auto-or- ganização. Longe do equilíbrio, nestes sistemas, a dissipação de energia e de matéria pode tornar-se fonte de ordem. É às estruturas em que essa dissipação se dá que se chama estruturas dissipativas. Elas são uma forma de organização supermolecular.

Na formação das estruturas dissipativas, o sistema torna-se específico e dependente, de maneira crítica, do mecanismo das transformações químicas que as determinam. Não existe lei universalmente válida donde possa ser deduzido, para cada valor das condições-limite, o seu comportamento geral; cada sistema constitui um problema singular; cada conjunto de reaç̧ões químicas que o determinam deve ser explorado de per si, pois pode determinar um comportamento qualitativamente distinto.

Enquanto as reaç̧ões "não-lineares", cujo efeito (a presença do produto de reacção) reage em compensação sobre a causa, são relativamente raras no mundo inorgânico, elas constituem praticamente a regra geral nos sistemas vivos, onde processos de auto-catálise, auto-inibição e catálise cruzada constituem os mecanismos clássicos de regulação que asseguram a coerência do funcionamento metabólico.

O mecanismo fundamental da transmissão e exploração de informação genética é, ele próprio, um mecanismo "não-linear". A informação genética é recopiada num mecanismo auto-catalítico de réplica do DNA, ao ritmo da multiplicação das células. Enquanto em equilíbrio e próximo dele, o sistema se mantém espacialmente homogéneo, longe do equilíbrio a difusão dos reagentes através do sistema e toda uma série de oscilações temporais, traduzidas noutras tantas estruturas dissipativas, conduzem a possíveis situações de instabilidade em que o sistema pode adoptar um comportamento que já não é periódico, mas estacionário, espacialmente estruturado.

Longe do equilíbrio, a própria homogeneidade do tempo é destruída, quer pela natureza global do espaço-tempo que confere ao sistema o comportamento de uma totalidade organizada, quer pela história que o aparecimento de tais estruturas implica e que é, em muitos casos, simples fatalidade. Uma vez tornado instável, o sistema fica aberto não a uma mas a várias possibilidades de saída que constituem outras tantas bifurcações na trajectória da sua possível evolução. A sua progressão para uma delas depende da natureza da flutuação que vier efectivamente a destabilizá-lo. Não é possível justificar essa progressão evocando apenas a sua composição química e/ou as condições-limite. De facto, não se pode deduzir destas o estado singular para o qual o sistema avança, pois a partir de cada bifurcação, outros estados lhe eram igualmente acessíveis[46].

É o carácter estritamente linear ou não-linear da causalidade no domínio da biologia que está em causa. Até onde e em que termos "acaso e necessidade" informam, conjuntamente ou não, o processo evolutivo em que a vida se desenrola?[47] A evolução genética aparece como fortemente marcada pelo acaso em que as estruturas dissipativas marcam e conduzem o rumo efectivo.

\section{CONCLUSÃO}

Do que fica dito pode concluirse que apesar dos estupendos avanços registados pela ciência relativamente à explicação em termos da Física e da Química de muitos dos fenómenos relacionados com a vida, as questões que se põem sobre a sua natureza e os cenários relativos à sua história continuam a ser inúmeros. Uma e outra resistem cruelmente, muito mais que as questões relativas à matéria inanimada, ao escalpelo do pensamento científico[48]. As questões sem resposta são tantas que dizer, hoje, que a vida na sua origem e natureza última é redutível a uma explicação cabal no quadro das leis físicas e dos processos químicos é muito mais um acto que se escuda nas maravilhas com que o progresso científico nos brinda, dia a 
dia, do que uma atitude científica alicerçada em factos comprovados.

\section{*Dept. de Química \\ Universidade de Coimbra \\ 3000 Coimbra - Portugal}

\section{REFERÊNCIAS}

1. A. M. Amorim da Costa, Da Vida e suas explicaçōes - Estereoquimica e Vitalismo in Química, Bol. Soc Port. Química, $n^{0} 68$ (1998), 24-27.

2. Idem, pg. 26.

3. H. Boerhaave, Traité de la vertu des médicamens, 1739 , p. 3 .

4. F. G. Donnan, The mystery of life in 1. Chem. Educ. 5 (1928), 1558-1570

5. P. Davies, Deus e a nova Fisica (Edições 70, Lisboa 1986, Col. Universo da Ciência, ${ }^{\circ} 1$ 1) p.76

6. E. Schrödinger, Vida, Espírito e Matéria (Lisboa, Publ. Europa-América, 1963), pp. 113-114; Idem, O Que é a Vida? Espírito e Matéria (Lisboa, Editorial Fragmentos Lda, 1989) p.74. Nota: Estas são duas edições diferentes de uma mesma obra de E. Schrödinger correspondente à série de Conferências que o autor proferiu, no Trinity College de Dublin, em 1943, sobre o tema "What is Life?" e no Trinity College de Cambridge, em 1956 sobre o tema "Mind and Matter". As nossas citações reportar-se-ão à edição mais recente, a da Editorial Fragmentos.

7. Idem, p.81

8. I. Prigogine e I. Stengers, A Nova Alianşa (Lisboa, Ed. Gradiva, 1987, Col. Ciência Aberta, no 14), pp. 276 277.

9. Idem, p. 277

10. Idem, cp. IX, pp. 328-359.

11. Idem, pp. 367-368.

12. E. Schrödinger, o. cit., p. 80

13. Idem, cp. VII, pp. $79-86$.

14. Idem, pp. 111-112

15. F. Crick, Vida, o mistério da sua origem e natureza (Ed. Gradiva, Lisboa, 1988, Col. Ciência aberta, n"23); Vários, As Origens da Vida (Ed.Rei dos Livros, Lisboa, 1997).

16. A. I. Oparin, Proiskhozhdenie Zhizni (Izd. Moskovs- kii Rabochii, Moskow, 1924).

17. I.B.S. Haldane, Rationalist Annual, 1929; Idem, Science and Human Life (Harper Bros, NY \& London. 1933).

18. F. Raulin, Pontos de vista modernos sobre a origem da vida in Bol. Soc. Port. Química, Série II, $n^{0}$ 13/14 (1983), pp. 20-21.

19. S. L. Miller, Science, 117 (1953), 528

20 A. M. Amorim da Costa, loc, cit., pp...26-27.

21. I. Rebek, Ir.,Synthetic self-replicating molecules in Sci. Am., Julho 1994, 34; J. Horgan, Trends in Evolution in Sci. Am., Fev., 1991, 100.

22. R. M. Lemmon, Chemical Evolution in Chem. Rev. 70 (1970), 95 e referências que apresenta; Vários. L Histoire de la Vie, 3 milliards d'années d'évolution, in Recherche, 296 (1997); C. de Dure, Construire une cellule - essai sur la nature et l'origine de la vie (Inter Ed.. Paris, 1990); A. Brack e F. Paulin, L Évolution chimique et les origines de la vie (Masson Ed., Paris, 1991); A. Eschenmoser and M. Volkankisarküker, Chemistry and the origin of Life in Helv, Chim. Acta, 79 (1976), 1249; J. P. Ferris, A quimica da Origem da Vida in Chemical and Engineering News, 62 (1984), 23-25. trad in Bol. Soc. Port. Química, Série II, n² 22 (1985), 518; H. D. Pflug, Evoluçào microbiana no precâmbrico Evidência Química e morfologia in Bol. Soc. Port. Química, Série II, no 22 (1985), 19-24; H. Maia, A Evolução Química na Terra e o Problema da Origem da Vida in Química e Sociedade, vol.1 (Soc. Port. de Química, Lisboa, 1990), pp. 27-48; A. M. Lobo, Moléculas da Vida in Quimica e Sociedade, vol.1 (Soc. Port. de Química, Lisboa, 1990), pp. 49-62.

23. A. I. Oparin, Origin of Life (MacMillan, Nova lorque, 1938) p. 101

24. H. C. Urey, The Planets: their origin and development (Yale Univ. Press, New Haven, Conn., 1952).

25. H. Stern, Science, 121 (1955), 144.

26. R. M. Lemmon, loc. cit., p. 97

27. I. B. S. Haldane, locs. cits; I. S. Shklovskii and C. Sagan, Inteligent Life in the Universe (Holden-Day, Inc., S. Francisco, Calif., 1966) p. 233.

28. F. Wöhler, Poggendorfís Ann. 12 (1828), 253-256; Idem, Ann. Chim. Phys, 37( 1828), 330-333; Idem, Quart. J. Sci. Art., Series 2, Part.1, April/June 1828, 491.

29. W.H. Warren, Contemporary reception of Wöhler's discovery of the synthesis of urea in J. Chem. Educ., 5 (1928), 1539-1553; J. H. Brooke, Wöhler's urea and its vital force - A veredict from the chemists in Ambix, 15 (1968), 84-114; P. S. Cohen and S. M. Cohen, Wöhler's synthesis of urea : how do the textbooks report it in I. Chem. Educ, 73 (1996), 883-886.

30. S. L. Miller, Ann. N. Y. Acad. Sci., 69 (1957), 260.

31. C. Ponnamperuma, R. M. Lemmon, R. Mariner and M. Calvin, Proc. Natl. Acad. Sci., U. S., 49 (1963) 737.

32. S. L. Miller and H. C. Urey, Science, 130 (1959), 245 .

33. C. Ponnamperuma, C. Sagan and R. Mariner, Nature, 199 (1963), $222 \mathrm{C}$

34. C. Ponnamperuma and P. Kirk, Nature, 203 (1964), 400

35. S.C. Lind and D.C. Bardwell, J. Am. Chem. Soc., 48 (1926), 2335.

36. W. Mund and W. Koch, Bull. Soc. Chim. Belges, 34 (1925), 119.

37. D. Shemin, Proc. 3rd Intern. Congress on Biochemistry, Brussels, 1955, p. 197.

38. G. W. Hodgson and C. Ponnamperuma, Proc. Natl. Acad. Sci., U. S., 59 (1968) 22.

39. S. W. Fox and K. Harada, I. Am. Chem. Soc., 82 (1960) 3745 .

40. S. W. Fox and T. V. Waehneldt, Biochim. Biophys. Acta, 160 (1968) 246

41. A. Kornberg, Enzymatic Synthesis of Deoxyribonucleic acid (Academic Press, N. Y., 1961) pp. 83-112.

42. M. Goulian, A. Kornberg and R. L. Sinsheimer, Proc. Natl. Acad. Sci., U. S., 58 (1967) 2321.

43. K. Dose, Evolução molecular e protobiologia - uma panorâmica in Bol. Soc. Port. Química, Série II, n?13/14 (1983), 22-25.

44. A. I. Oparin, The chemical Origin of Life (Charles Thomas Publ.. Chicago III., 1964)

45. S. W. Fox, K. Harada and J. Kendrick, Science, 129 (1959) 1221; S. W. Fox, K. Harada and A. Vegotsky, Experimentia, 15 (1959), 81; S. W. Fox an K. Dose, Molecular Evolution and the origin of life (Marcel Dekker, N. Y., 2nd edition, 1977).

46. I. Prigogine e I. Stengers, , o. cit., pp. 206-236.

47. 1. Monod, Le Hasard et la Nécessité - Essai sur la Philosophie naturelle de la biologie (Ed. Du Seuil, Paris. 1970).

48. L'Histoire de la vie - 3 milliards d'années d'évolution in loc. cit., Editorial. 


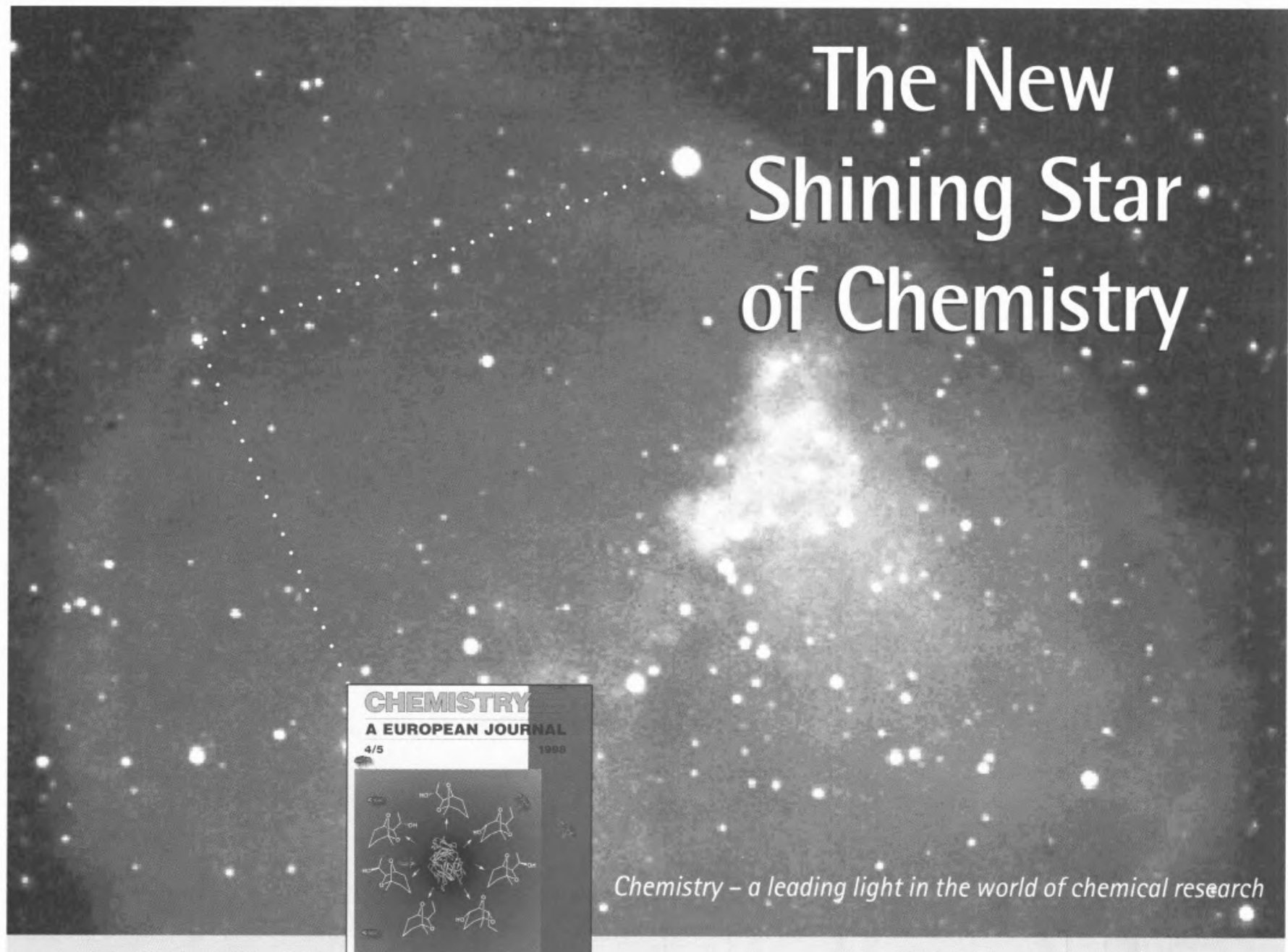

A new star has appeared in the heaven of chemistry.

Chemistry-A European Journal

is an international forum for the 1999. Volume 5.12 issues publication of the brightest full per year. ISSN 0947-6539 papers. With Nobel laureate J.-M. Lehn as chairman of the Editorial Board, Chemistry has taken its rightful place among

leading scientific journals. Its ISI Impact Factor of 4.828 places Chemistry hot on the heels of the Journal of the

American Chemical Society.

Chemistry publishes work from all fields of chemistry.

Its success has come from combining first-rate full papers from international top authors with great features like

"Concepts", which provide an insightful guide to new areas and new angles on familiar problems.

Chemistry-A European Journal is a joint project of many national chemical societies. Profit from the highest quality. Order your free sample copy today!

\section{Order Form}

Please enter our/my 1999 subscription to: Chemistry - A European Journal

\section{at the institutional rate of:}

口 DM 1498,- $\quad$ (Germany/Austria)

: $\square$ SFR 1398,-- (Switzerland)

$: \square$ US\$ 948, - $^{*}$ (other countries within Europe)

: $\square$ US\$ 998,-- (all other countries)

\section{at the personal rate"* of:}

$\square$ DM 178,- (Germany/Austria)

: $\square$ SFR 154,- (Switzerland)

- US\$ 108,- $\quad$ (other countries within Europe)

口 US\$ 128,- (all other countries)

*Prices include postage and handling charges.

"valid only for members of the owning societies

from Belgium, Czech Republic, France, Germany, Greece, Hungary, Italy, The Netherlands, Poland, Portugal,

Spain, and Sweden.

$: \square$ Please send me a free sample copy

Please tick: $\square$ private $\square$ business

Name

Address

Town, Postcode

Country

Membership-No.

Signature
Please return this order form to your local bookseller or to:

\section{Customers in Germany,} Austria \& Switzerland: WILEY-VCH Reader Service

P. O. Box 1011 61, D-69451 Weinheim, Germany

Phone:+49 6201 606-458

Fax: +49 6201 606-117 e-mail: subservice@wiley-vch.de

Customers in all other areas: John Wiley \& Sons, Ltd.

Journals Administration Department 1 Oldlands Way Bognor Regis West Sussex, P022 9SA, England

Phone: +44(0) 1243779777

Fax: +44 (0) 1243843232

e-mail:cs-journals@wiley.co.uk 